\title{
Liquefaction-induced ground subsidence extracted from Digital Surface Models and its application to hazard map of Urayasu city, Japan
}

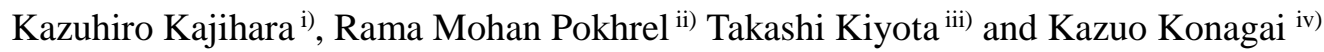

\begin{abstract}
i) Graduate Student, Yokohama National University, 79-5, Tokiwadai, Hodogaya-ku, Yokohama-shi, Kanagawa, 240-8501, Japan
ii) JSPS Postdoctoral Research fellow, IIS, the University of Tokyo, Be 206, 4-6-1, Komaba, Meguro-ku, Tokyo, 153-8505, Japan iii) Associate Professor, IIS, the University of Tokyo, Be 206, 4-6-1, Komaba, Meguro-ku, Tokyo, 153-8505, Japan

iv) Professor, Yokohama National University, 79-5, Tokiwadai, Hodogaya-ku, Yokohama-shi, Kanagawa, 240-8501, Japan
\end{abstract}

\begin{abstract}
The major problems associated with liquefaction-induced ground subsidence are tilting of houses, buckling of roads, lifelines cut off, etc. For the mitigation and preparedness over the liquefaction-induced damage, a detailed study on prediction of ground subsidence for future earthquake is important. On the $11^{\text {th }}$ of March 2011, the Off the Pacific Coast of Tohoku Earthquake $\left(\mathrm{M}_{\mathrm{W}}=9\right)$ hit Japan and caused severe liquefaction in Urayasu City, Chiba Prefecture. In this study, in order to investigate the relationship between liquefaction potential, $\mathrm{P}_{\mathrm{L}}$, and liquefaction-induced subsidence which occurred in the 2011 earthquake, liquefaction assessment is first carried out by using a number of boreholes and relevant soil test data from Urayasu city. Then, the liquefaction-induced road subsidence is extracted from a set of the Digital Surface Models (DSMs) from airborne LiDAR (Light Detection And Ranging) surveys before (2006) and after (2011) the earthquake. The extracted subsidence from the DSMs indicates that the liquefaction-induced road subsidence is larger for the residential roads than that of the main roads, thus the relationship between $P_{\mathrm{L}}$ and road subsidence is different for each type of road. Finally, an attempt is made to apply the obtained $\mathrm{P}_{\mathrm{L}}$ and road subsidence relations to attain a unique hazard map for Urayasu city.
\end{abstract}

Keywords: Liquefaction potential, Soil subsidence, Urayasu city, Reclaimed land

\section{INTRODUCTION}

Soil liquefaction is one of the most serious geotechnical phenomenon in an earthquake that can cause severe ground subsidence, lateral spreading, tilting of structures and uplift of light underground hollow structures especially in loose alluvial deposits and/or reclaimed lands. Three quarters of Urayasu City in Chiba Prefecture, Japan had been earth-filled in since 1966 till 1985, and Yasuda et al. (2012) reported that about $85 \%$ of the Urayasu city were heavily damaged due to soil liquefaction in the $11^{\text {th }}$ of March 2011, the Off the Pacific Coast of Tohoku Earthquake.

In Urayasu city, sand dredged from the bottom of the Tokyo bay was deposited along the shore line, and extended the beach about $2 \mathrm{~km}$ farther into the body of water of the Tokyo Bay. Then, it was covered with sand transported from the Boso Peninsula (Yasuda et al., 2012). With the presence of the weakly deposited earthfill, the greater part of Urayasu city has been long susceptible to liquefaction.

Liquefaction hazard maps had been prepared in many autonomous bodies in Japan to assess the impact of liquefaction in each target area. However, they provide information of only liquefaction event probability in a scenario earthquake, and no quantitative indicator of damage extent such as the expected amount of ground subsidence. Moreover, many uncertainties in liquefaction assessment methods, which were pointed out in earlier studies (e.g. Yasuda et al, 2009), had not been taken into account in an explicit manner.

This study aims to investigate the relationship between liquefaction potential and liquefaction-induced road subsidence in Urayasu city, and to apply this relationship to building a more useful hazard map showing expected liquefaction-induced road subsidence, which subsidence can have an important effect on every rescue and restoring operations.

For this purpose, necessary soil parameters for liquefaction assessment were first estimated based on borehole logs and soil testing data available in Urayasu city. Secondly, values of liquefaction potential $\left(\mathrm{P}_{\mathrm{L}}\right)$ were estimated at various locations in the city on a Geographic Information System (GIS). Thirdly, the extents of road subsidence were extracted in an exact manner from the soil subsidence map (Konagai et al., 2013), and compared with the estimated $P_{L}$ values to prepare a quantitative hazard map of liquefactioninduced road subsidence for Urayasu City. 


\section{LIQUEFACTION RISK ASSESMENT}

In the liquefaction potential zoning, the mandatory processes include the collection of geotechnical data from boreholes and estimation of geotechnical parameters to evaluate the values of liquefaction potential. This study selected 109 boreholes in Urayasu City as shown in Fig.1

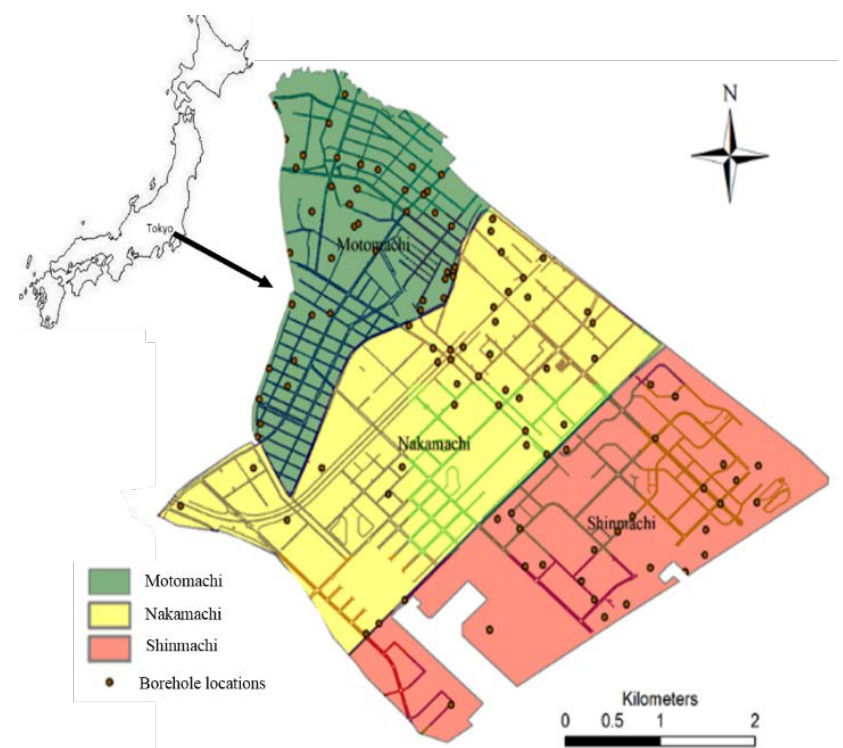

Fig. 1. Location of study area with borehole points (Urayasu city, 2012; Chiba Prefecture, 2014)

\subsection{Soil parameter estimation}

According to the Specifications for Highway Bridges (2012), soil parameters such as fines content (FC), plasticity index $\left(\mathrm{I}_{\mathrm{p}}\right)$, mean particle size $\left(\mathrm{D}_{50}\right)$, unit weight of soil $(\gamma)$ and ground water level are indispensable for evaluating values of liquefaction potential. These parameters are only available at 23 boreholes out of the 109 boreholes in Urayasu City though descriptive soil logs are available at all 109 borehole locations. Thus, the required soil parameters for the remaining 86 boreholes are to be estimated only from available pieces of information.

Firstly, the surface soil layer of the Urayasu city was schematically divided into 5 layers as shown in Fig. 2, based on the continuity of each layer and their SPT-N values and FC. The greater part of the uppermost fill is composed of sand dredged from the sea bed. The middle layer is composed of silt. As1 layer is the upper alluvial sand deposit with relatively high SPT-N values. As2 layer is the lower alluvial sand deposit with relatively lower SPT-N values and contains more fines than that the upper As1 layer has. Note that, the alluvial clay layer was not considered in the liquefaction assessment because there had been no evidence of liquefaction in clay during past earthquakes.

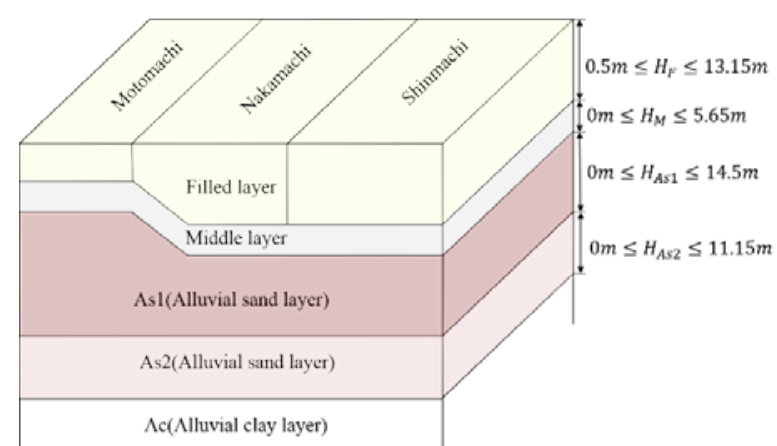

Fig. 2. Layout of the soil layers in Urayasu city

In order to estimate the $\mathrm{FC}$ values for the boreholes without laboratory test, the correlation with SPT-N values has been used frequently (Yasuda et al., 2009). Figure 3 shows the relationship between FC and normalized SPT-N value, $\mathrm{N}_{1}$, for the 23 boreholes. Figure 3 indicates that the value of FC decreases with increase in $\mathrm{N}_{1}$ value, and the trend can be expressed by the following equation.

$$
\mathrm{FC}= \begin{cases}\frac{848}{1.4 \mathrm{~N}_{1}+7.84}-11.6 & \left(N_{1}<46.5\right) \\ 0 & \left(N_{1} \geq 46.5\right)\end{cases}
$$

Figure 4 shows the relationship between FC and Ip of the soil layers. According to the Specifications for Highway Bridges (2012), the soil layer that the Ip exceeds the threshold value ( $I p=15$ ) will be excluded in the liquefaction assessment. As presented in Fig. 4, the middle layer plotted with a blue circle symbol shows that the Ip value exceeds 15 when the FC becomes about $70 \%$, while it is about $80 \%$ for the other layers. In this study, these values of FC were set as the threshold value in which liquefaction is likely to occur.

The average values of the $D_{50}$ and $\gamma$ of the soils were set for each layer. In addition, the groundwater level was set at $1.5 \mathrm{~m}$ below the ground surface for the entire stretch of the target zone.

Finally, liquefaction assessment was conducted at each borehole location and liquefaction potential index, $\mathrm{P}_{\mathrm{L}}$, defined by Iwasaki et al. (1982) was calculated. The input ground acceleration in the calculation was chosen by considering the soil structure of Urayasu City as shown in Figs. 1 and 2. For Motomachi area, the peak ground acceleration of 174.3 gal (resultant values of $X$, Y, Z components) observed at K-net Urayasu Station (N35.6537 deg., E139.9023 deg.) in the same area was used. For Nakamachi and Shinmachi areas, 200 gal was adopted as the peak ground acceleration, which was based on the one-dimensional seismic response analysis reported by Ishikawa et al. (2014). 


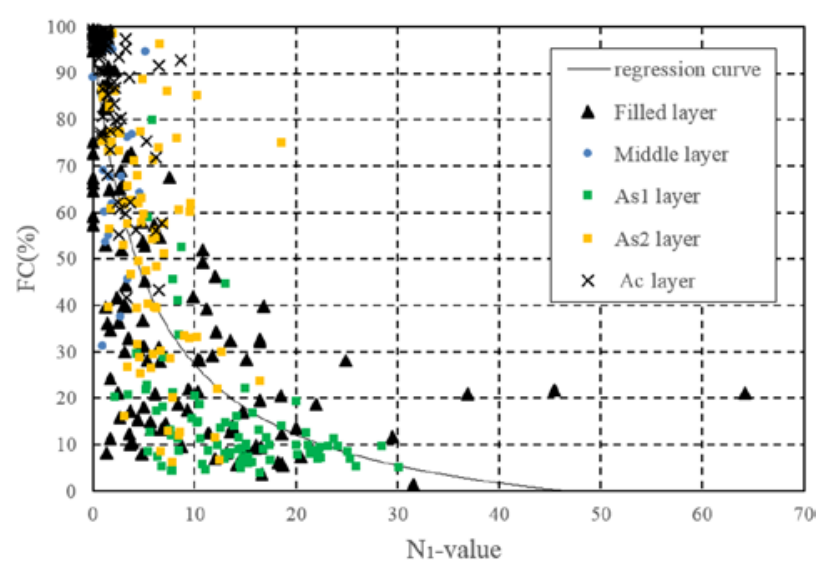

Fig. 3. Relationship between $\mathrm{N}_{1}$-values and fines content

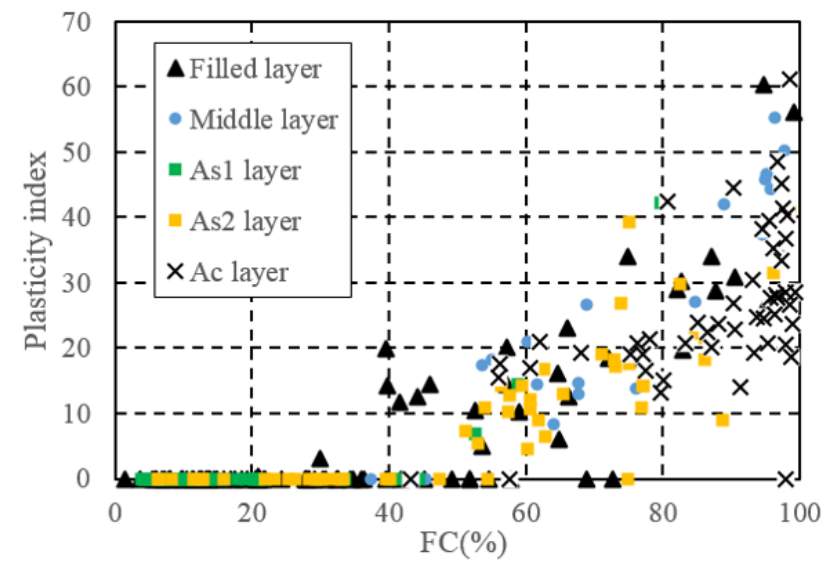

Fig. 4. Relationship between fines content and plasticity index

\subsection{Mapping of liquefaction potential $\left(\mathrm{P}_{\mathrm{L}}\right)$}

Since the liquefaction potential surface is considered to change in space in a continuous manner, it is not practical to obtain its value point by point. Therefore, a Kriging method was taken herein to predict the value of the liquefaction potential at a given point by computing a weighted average of the known values. In kriging, the first step is to examine the data to identify its spatial structure, which is often represented by the empirical semivariogram (Isaaks and Srivastava, 1989). A semivariogram shows the relationship between semivariance and the distance between all the pairs of available data points, as schematically illustrated in Fig. 5.

The experimental semivariance for $\mathrm{P}_{\mathrm{L}}$ is calculated by using the following Eqn. (2) (Pokhrel et al. 2012, 2013):
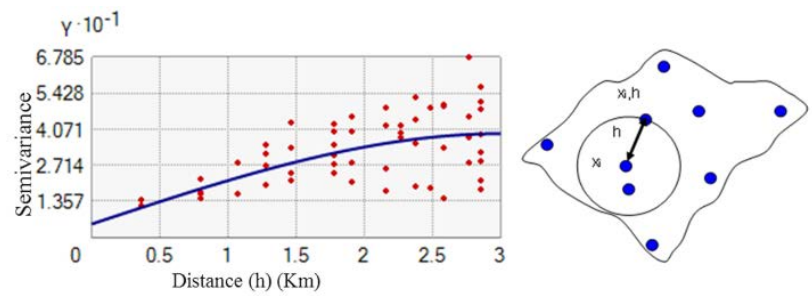

Fig. 5. Kriging variogram model

$$
\gamma(h)=\frac{1}{2 N(h)} \sum_{i=1}^{N(h)}\left(P_{L}(i)-P_{L}(i, h)\right)^{2}
$$

where, $\gamma(h)$ is the estimated value of the semivariance for a distance $h ; N(h)$ is the number of experimental pairs separated by $h ; P_{L}(i)$ and $P_{L}(i, h)$ are the values of the variables $P_{\mathrm{L}}$ at $(i)$ and $(i, h)$ positions, respectively.

The map of the study area was divided into three parts, Motomachi area, Nakamachi area and Shinmachi area. The map of the spatial variation of $\mathrm{P}_{\mathrm{L}}$ was prepared area by area, and combined as a single map as shown in Fig. 6. This figure shows that the greater part of Nakamachi and Shinmachi areas have large $P_{L}$ values, while Motomachi area has relatively small $\mathrm{P}_{\mathrm{L}}$ values, which is consistent with the fact that minor evidence of liquefaction was sparsely observed in Motomachi area.

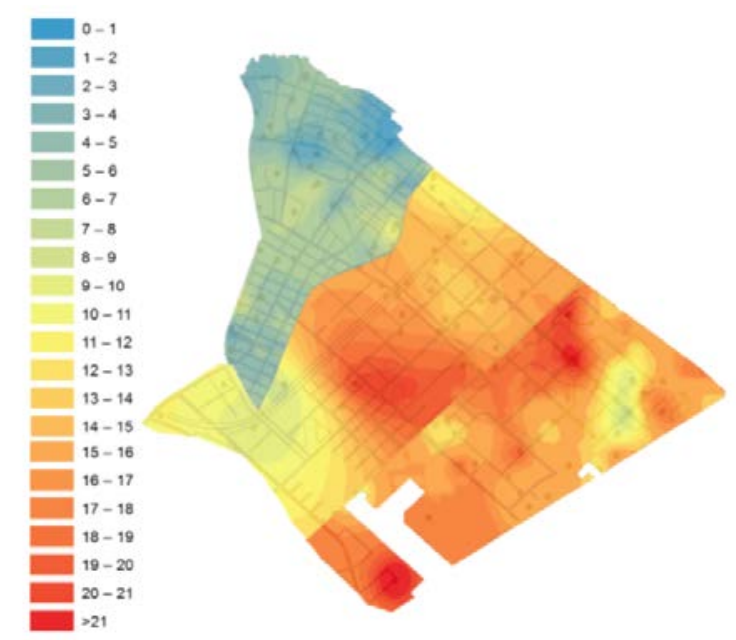

Fig. 6. Liquefaction potential distribution map of examined area of Urayasu city

\section{RELATION BETWEEN LIQUEFACTION POTENTIAL AND ROAD SUBSIDENCE}

\subsection{Extraction of road subsidence}

Values of road subsidence were extracted from the soil subsidence map (Konagai et al., 2013). The subsidence map (Fig. 7) was prepared firstly by comparing two sets of DSMs before and after the earthquake in 2006 and 2011, respectively, and then subtracting tectonic displacements from the increments in elevations (Konagai et al 2013). 


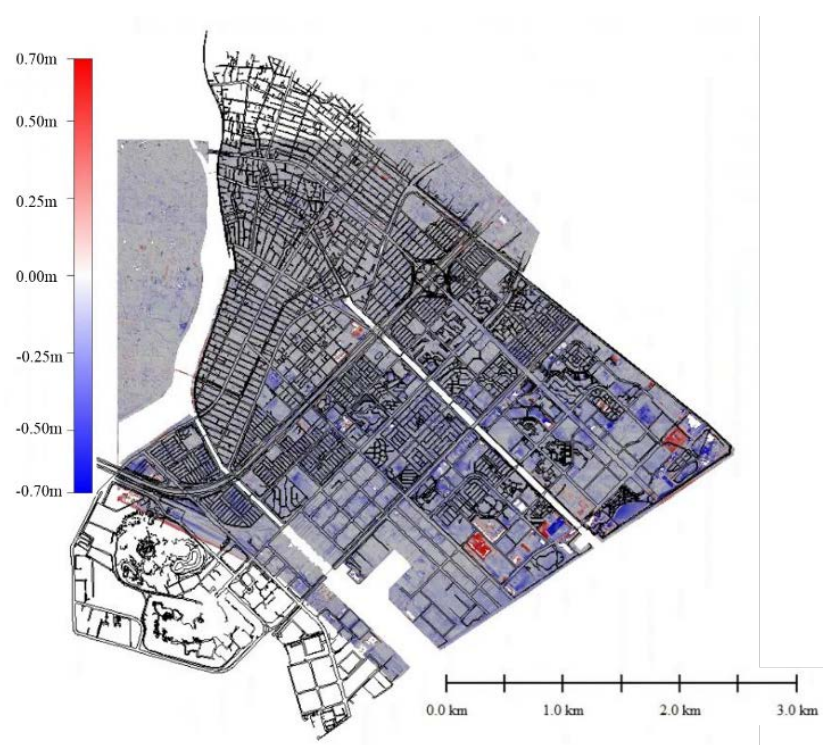

Fig. 7. Soil subsidence map of Urayasu city (Konagai et al., 2013)

Thus, this raster dataset coming with a colour-bar indicates the changes in elevation only due to the soil liquefaction. Average values of road subsidence over the road width were extracted as shown in Fig. 8. Note that for the extraction of road subsidence, both ends of the road were excluded to avoid a possible error due to the presence of plants lining the road.

Figure 9 shows the target roads in this study. The subsidence was extracted at 160 points along the different types of roads, i.e., highways, main roads and residential roads. These points were chosen to cover equally the three major areas in Urayasu City, Motomachi, Nakamachi and Shinmachi.

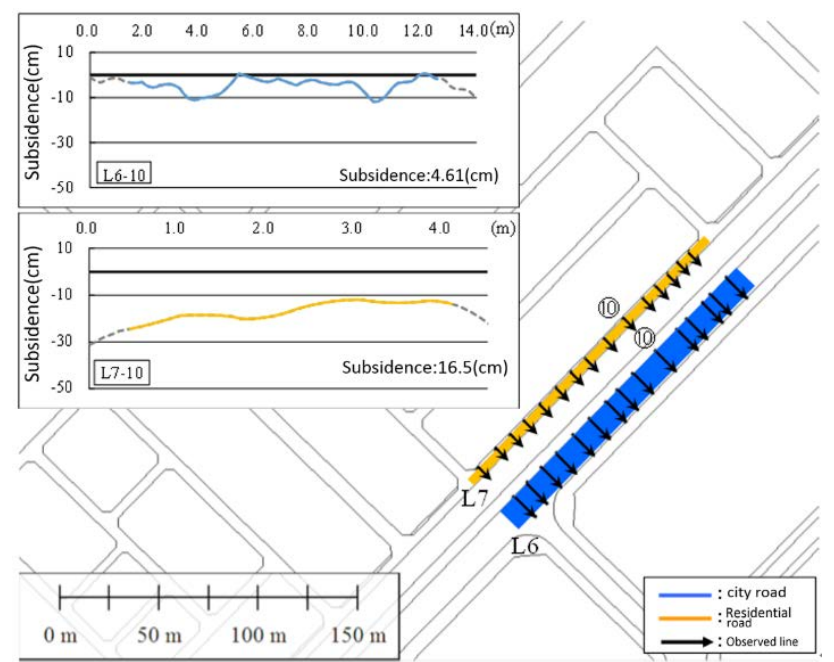

Fig. 8. Profile across the road along observed lines (based on Suyama, 2013)

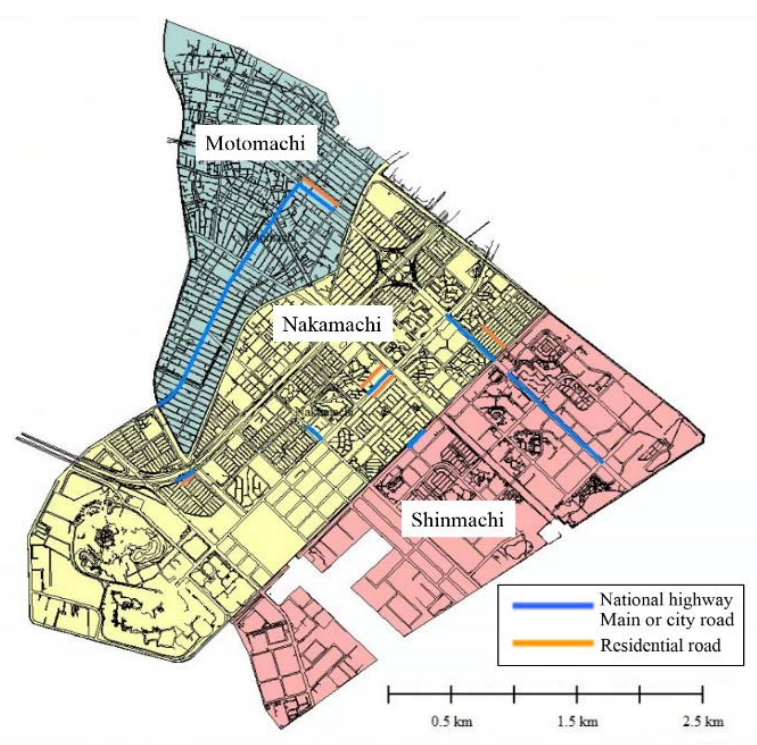

Fig. 9. Location of subsidence extraction data

\subsection{Relationship between PL value and road subsidence}

Figure 10 shows the relationship between liquefaction potential indices $\left(\mathrm{P}_{\mathrm{L}}\right)$ and averaged values of road subsidence at all points shown in Fig.9. In general, the values of road subsidence increase with an increase in the $\mathrm{P}_{\mathrm{L}}$ value. The points on the scatter plot of $\mathrm{P}_{\mathrm{L}}$ value vs settlements are clustered into three groups in terms of pavement-roadbed thickness, which data set is provided by Urayasu City (2012). Typically, the pavement-roadbed thicknesses are larger than 115 $\mathrm{cm}$, between $65 \mathrm{~cm}$ and $90 \mathrm{~cm}$, and less than $65 \mathrm{~cm}$ for national highways, main roads and residential roads, respectively. The results show clearly that an increase in the values of road subsidence with the increase of PL value is more pronounced for thinner pavementroadbed layers than those for thicker ones. The thinner pavement-roadbed layers are, the larger is the dispersion of the subsidence values. Linear regression lines are drawn in Fig. 10 to highlight the abovementioned trend.

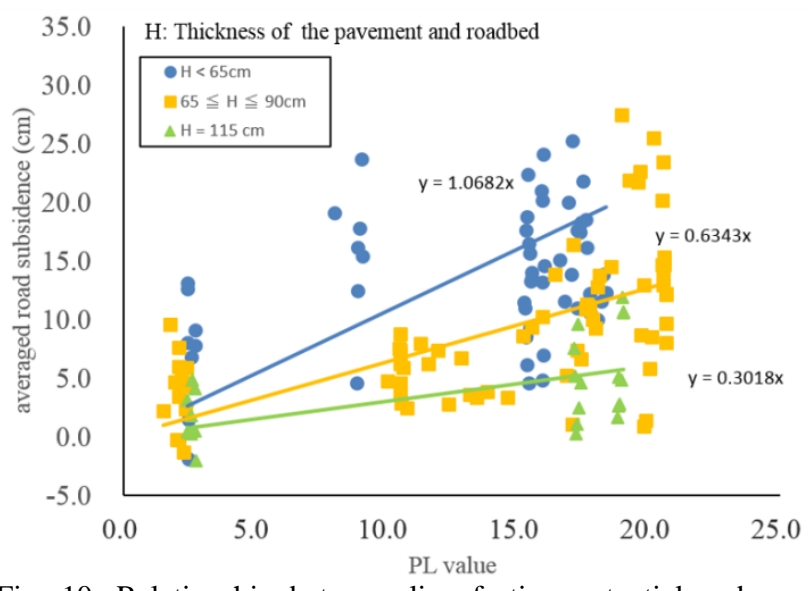

Fig. 10. Relationship between liquefaction potential and road subsidence 


\section{CONSTRUCTION OF NEW HAZARD MAP}

Given the $P_{L}$ distribution map shown in Fig. 6 and the relationship between $\mathrm{P}_{\mathrm{L}}$ and road subsidence in Fig. 10, road-subsidence risk can be evaluated as shown in Fig. 11. In this process, each pavement-roadbed layer thickness was determined category-wise-constant for each road type as shown in Table 1 , because the road structure information available in the report of Urayasu City (2012) does not cover the entire target roads.

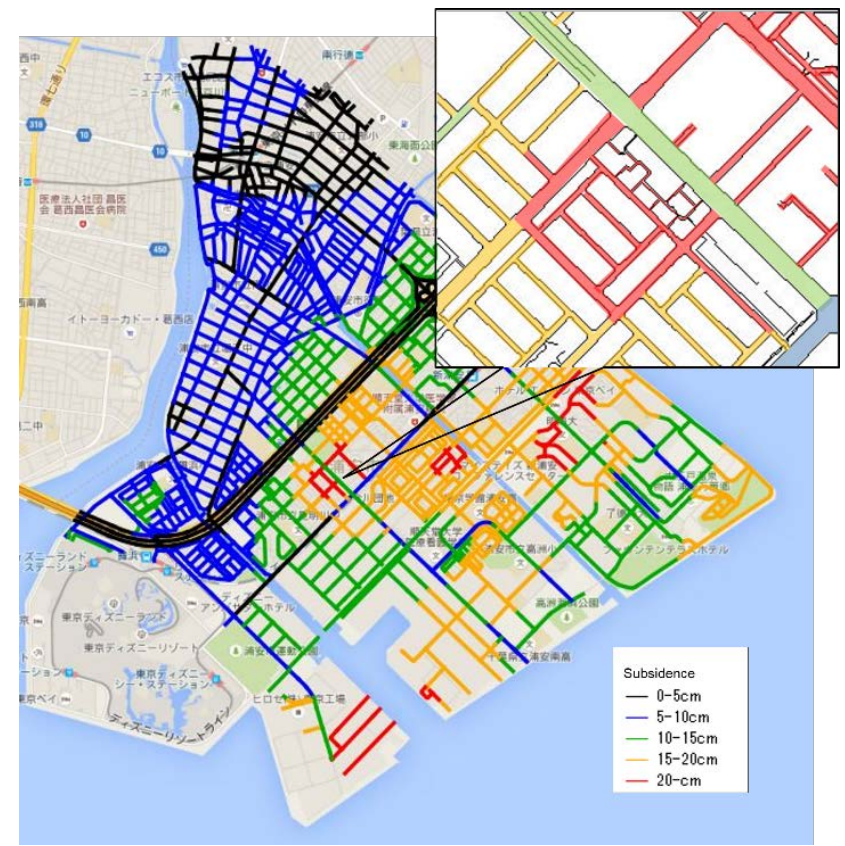

Fig. 11. Proposed liquefaction hazard map

Note that the expressway running through the Uraysu city is assumed not to have been subsided in this map. This map shows that the road subsidence can differ even among roads with the same $\mathrm{P}_{\mathrm{L}}$ values, and the spatial pattern of the road subsidence shown in Fig.11 is consistent on the whole with that described in the damage investigation report of the Urayasu city (2012). This new hazard map is considered to be useful for not only the assessment of liquefaction-induced damage but also route selection for emergency vehicles.

\begin{tabular}{|l|l|}
\hline $\begin{array}{l}\text { Table 1. Thickness } \\
\text { of the pavement and } \\
\text { roadbedRoad type }\end{array}$ & $\begin{array}{l}\mathrm{H} \text { : Thickness of the pavement } \\
\text { and roadbed }(\mathrm{cm})\end{array}$ \\
\hline $\begin{array}{l}\text { National road } \\
\text { Prefectural road }\end{array}$ & $H=115$ \\
\hline City road & $65 \leq H \leq 90$ \\
\hline Residential road & $H<65$ \\
\hline
\end{tabular}

\section{CONCLUSION}

A quantitative discussion was made in this study about the relationship between liquefaction potential
$\left(\mathrm{P}_{\mathrm{L}}\right)$ and liquefaction-induced road subsidence based upon quantitative data of Urayasu City that has suffered from the 2011 off the pacific coast of Tohoku Earthquake. Liquefaction assessment was carried out based on the estimated soil parameters, and the spatial distribution of $\mathrm{P}_{\mathrm{L}}$ values estimated from 109 borehole logs was summarized as a map. Then, it was compared with corresponding values of road subsidence extracted from the liquefaction-induced ground subsidence map (Konagai et al., 2013). The result shows that the road subsidence increases with the increase in the $\mathrm{P}_{\mathrm{L}}$ value. In particular, the thicker the pavement-roadbed layer is, the smaller is the road subsidence. Using the obtained relationship between $\mathrm{P}_{\mathrm{L}}$ values and road subsidence values, a new hazard map showing liquefaction-induced road subsidence for different road types was prepared.

\section{ACKNOWLEDGEMENTS}

The borehole logs and relevant experimental data used in this study were provided by the Technical Committee on measures against liquefaction, Urayasu City (chaired by Prof. Ishihara).

\section{REFERENCES}

1) Chiba Prefecture: Geotechnical Environment Information Bank in Chiba Prefecture, http://www.pref.chiba.lg.jp/suiho/chishitsu.html Japanese), accessed in 2014.

2) Isaaks, E.H., Srivastava, R.M. (1989): An Introduction to Applied Geostatistics. Oxford University press, Oxford, 561pp.

3) Ishikawa K., Yasuda S., Ikarashi S. (2014): Study on the reasonable liquefaction prediction of Urayasu in case of the Great East Japan Earthquake based on Representative Soil Profile Models. The $14^{\text {th }}$ Japan Earthquake Engineering Symposium, pp. 2347-2356 (in Japanese).

4) Iwasaki, T., Tokida, K., Tatsuoka, F., Watanabe, S., Yasuda, S., and Sato, H. (1982): Microzonation for soil liquefaction potential using simplified methods. Proceedings of 3rd International Earthquake Microzonation Conference, Seattle, pp. 1319-1330.

5) Japan road association. (2012): Seismic designed specifications for Highway bridge volume $V$.

6) Konagai, K., kiyota, T., Suyama, S., Asakura, T., Shibuya, K., Eto, C. (2013): Maps of soil subsidence for Tokyo bay shore areas liquefied in the March $11^{\text {th }}, 2011$ off the pacific Coast of Tohoku Earthquake. Soil Dynamics and Earthquake Engineering, Vol.53, pp.240-253.

7) Pokhrel, R.M., Kuwano, J., Tachibana, S. (2012): Geostatistical analysis for spatial evaluation of liquefaction potential in Saitama City. Lowland Technology International, vol. 14, No.1, pp.45-51.

8) Pokhrel, R.M., Kuwano, J., Tachibana, S. (2013): A kriging method of interpolation used to map liquefaction potential over alluvial ground. Engineering Geology, Vol. 152, pp. 2637.

9) Suyama, S. (2013): Soil subsidence map of the liquefied Tokyo bay area and its exploitation in multiple factor analyses of liquefaction impact, A master thesis submitted to department of Civil Engineering, University of Tokyo (in Japanese).

10) Urayasu City. (2012): Data compiled by the Technical 
Committee on measures against Liquefaction,

http://www.city.urayasu.chiba.jp/menu11324.html (Japanese).

11) Yasuda, S., Ishida, E. Hosokawa, N. (2009): Several attentions necessary for the mapping on liquefaction, JSCE journal, A1, Vol. 65, No1, pp.188-194 (in Japanese).

12) Yasuda, S., Harada, K., Ishikawa, K, Kanemaru, Y. (2012):

Characteristics of liquefaction in Tokyo Bay area by the 2011

Great East Japan Earthquake. Soils and Foundations, Vol. 52(5): pp. 793-810 